\title{
The Lithium Problem-The Excess Isn't Missing; It Was Never There
}

\author{
J. C. Botke \\ Nogales, Arizona, USA \\ Email: jcbotke(at)gmail.com
}

How to cite this paper: Botke, J.C. (2021) The Lithium Problem-The Excess Isn't Missing; It Was Never There. Journal of High Energy Physics, Gravitation and Cosmology, 7, 320-323.

https://doi.org/10.4236/jhepgc.2021.71015

Received: December 20, 2020

Accepted: January 19, 2021

Published: January 22, 2021

Copyright (c) 2021 by author(s) and Scientific Research Publishing Inc. This work is licensed under the Creative Commons Attribution International License (CC BY 4.0).

http://creativecommons.org/licenses/by/4.0/

\begin{abstract}
In this note, we present a result from an earlier work which shows that the so-called Lithium problem is nothing more than the consequence of several reactions being absent from the commonly used BBN software package.
\end{abstract}

\section{Keywords}

Big Bang Nucleosynthesis, Lithium Problem

\section{The Lithium Problem}

The so-called Lithium problem refers to the discrepancy between the calculated density of Lithium at the end of Big Bang nucleosynthesis and the density deduced from observations with the calculated density being about 3 times greater than the observed value. The general viewpoint has been that the calculated value is correct and that some unknown process has removed the excess Lithium subsequent to nucleosynthesis. What we incidentally discovered during the development of a comprehensive new model of cosmology [1] is that it is the calculated value that is wrong and the reason for this is that several known Lithium reactions are not included in the standard BBN software package [2]. Because this discovery is buried within a discussion concerning cosmology, we thought that it would be useful to present this result on its own for the benefit of researchers concerned with the problem. The model, the method used to calculate the nucleosynthesis reaction rates, and the references for the reaction data are presented in [1] so please refer to that paper for the details. Note that in the new model, the temperature at the time that nucleosynthesis proper began is lower than the corresponding temperature assumed in the standard model. As a result, the curves shown here are similar to but not exactly the same as those of the standard model. The most notable difference is that the new model nucleosyn- 
thesis is compressed in time relative to that of the standard model.

In Table 1, we list all the reactions we were able to find by searching the internet. For each reaction entry, we include a letter " $y$ " to indicate that the reaction is included in the standard BBN code and a blank otherwise.

During the development of our new model of cosmology, we ran a number of simulations with different initial particle densities and these are shown in [1]. A single example will be sufficient for our purpose and for this, we chose to show

Table 1. List of reactions.

\begin{tabular}{|c|c|c|c|}
\hline Reaction & BBN & Reaction & BBN \\
\hline p Production & & ${ }^{6} \mathrm{Li},{ }^{7} \mathrm{Li},{ }^{7} \mathrm{Be}$ Production & \\
\hline $\mathrm{n} \rightarrow \mathrm{p}+\mathrm{e}^{-}+\bar{v}$ & $\mathrm{y}$ & ${ }^{4} \mathrm{He}+{ }^{3} \mathrm{H} \rightarrow{ }^{7} \mathrm{Li}+\gamma$ & $\mathrm{y}$ \\
\hline d Production & & ${ }^{4} \mathrm{He}+{ }^{3} \mathrm{He} \rightarrow{ }^{7} \mathrm{Be}+\gamma$ & $\mathrm{y}$ \\
\hline $\mathrm{n}+\mathrm{p} \rightarrow \mathrm{d}+\gamma$ & $\mathrm{y}$ & ${ }^{4} \mathrm{He}+\mathrm{d} \rightarrow{ }^{6} \mathrm{Li}+\gamma$ & $\mathrm{y}$ \\
\hline${ }^{3} \mathrm{H} \&{ }^{3} \mathrm{He}$ Production & & ${ }^{3} \mathrm{He}+{ }^{3} \mathrm{H} \rightarrow{ }^{6} \mathrm{Li}+\gamma$ & $\mathrm{y}$ \\
\hline $\mathrm{d}+\mathrm{d} \rightarrow{ }^{3} \mathrm{H}+\mathrm{p}$ & $\mathrm{y}$ & ${ }^{4} \mathrm{He}+{ }^{3} \mathrm{H} \rightarrow{ }^{6} \mathrm{Li}+n$ & \\
\hline $\mathrm{d}+\mathrm{d} \rightarrow{ }^{3} \mathrm{He}+\mathrm{n}$ & $\mathrm{y}$ & ${ }^{6} \mathrm{Li},{ }^{7} \mathrm{Li},{ }^{7} \mathrm{Be}$ Exchange & \\
\hline $\mathrm{d}+\mathrm{n} \rightarrow{ }^{3} \mathrm{H}+\gamma$ & $\mathrm{y}$ & ${ }^{6} \mathrm{Li}+\mathrm{n} \rightarrow{ }^{7} \mathrm{Li}+\gamma$ & $\mathrm{y}$ \\
\hline $\mathrm{d}+\mathrm{p} \rightarrow{ }^{3} \mathrm{He}+\gamma$ & y & ${ }^{6} \mathrm{Li}+\mathrm{p} \rightarrow{ }^{7} \mathrm{Be}+\gamma$ & $\mathrm{y}$ \\
\hline${ }^{4} \mathrm{He}$ Production & & ${ }^{6} \mathrm{Li}+\mathrm{d} \rightarrow{ }^{7} \mathrm{Be}+\mathrm{n}$ & $\mathrm{y}$ \\
\hline $\mathrm{d}+\mathrm{d} \rightarrow{ }^{4} \mathrm{He}+\gamma$ & & ${ }^{6} \mathrm{Li}+\mathrm{d} \rightarrow{ }^{7} \mathrm{Li}+\mathrm{p}$ & $\mathrm{y}$ \\
\hline${ }^{3} \mathrm{H}+\mathrm{d} \rightarrow{ }^{4} \mathrm{He}+\mathrm{n}$ & $\mathrm{y}$ & ${ }^{6} \mathrm{Li}+{ }^{3} \mathrm{H} \rightarrow{ }^{7} \mathrm{Be}+\mathrm{n}+\mathrm{n}$ & \\
\hline${ }^{3} \mathrm{H}+\mathrm{p} \rightarrow{ }^{4} \mathrm{He}+\gamma$ & $\mathrm{y}$ & ${ }^{6} \mathrm{Li}+{ }^{3} \mathrm{H} \rightarrow{ }^{7} \mathrm{Li}+\mathrm{d}$ & \\
\hline${ }^{3} \mathrm{He}+\mathrm{d} \rightarrow{ }^{4} \mathrm{He}+\mathrm{p}$ & $\mathrm{y}$ & ${ }^{6} \mathrm{Li}+{ }^{3} \mathrm{He} \rightarrow{ }^{7} \mathrm{Be}+\mathrm{d}$ & \\
\hline${ }^{3} \mathrm{He}+\mathrm{n} \rightarrow{ }^{4} \mathrm{He}+\gamma$ & $\mathrm{y}$ & ${ }^{7} \mathrm{Li}+\mathrm{p} \rightarrow{ }^{7} \mathrm{Be}+\mathrm{n}$ & \\
\hline${ }^{3} \mathrm{H}+{ }^{3} \mathrm{H} \rightarrow{ }^{4} \mathrm{He}+\mathrm{n}+\mathrm{n}$ & $\mathrm{y}$ & ${ }^{7} \mathrm{Li}+{ }^{3} \mathrm{He} \rightarrow{ }^{6} \mathrm{Li}+{ }^{4} \mathrm{He}$ & \\
\hline${ }^{3} \mathrm{He}+{ }^{3} \mathrm{H} \rightarrow{ }^{4} \mathrm{He}+\mathrm{d}$ & $\mathrm{y}$ & ${ }^{7} \mathrm{Li}+{ }^{3} \mathrm{He} \rightarrow{ }^{7} \mathrm{Be}+{ }^{3} \mathrm{H}$ & \\
\hline${ }^{3} \mathrm{He}+{ }^{3} \mathrm{H} \rightarrow{ }^{4} \mathrm{He}+\mathrm{n}+\mathrm{p}$ & $\mathrm{y}$ & ${ }^{7} \mathrm{Be}+\mathrm{n} \rightarrow{ }^{7} \mathrm{Li}+\mathrm{p}$ & $\mathrm{y}$ \\
\hline${ }^{3} \mathrm{He}+{ }^{3} \mathrm{He} \rightarrow{ }^{4} \mathrm{He}+\mathrm{p}+\mathrm{p}$ & $\mathrm{y}$ & ${ }^{6} \mathrm{Li},{ }^{7} \mathrm{Li},{ }^{7} \mathrm{Be}$ Breakup & \\
\hline Exchange Reactions & & ${ }^{6} \mathrm{Li}+\mathrm{n} \rightarrow{ }^{4} \mathrm{He}+{ }^{3} \mathrm{H}$ & $\mathrm{y}$ \\
\hline${ }^{3} \mathrm{He}+\mathrm{n} \rightarrow{ }^{3} \mathrm{H}+\mathrm{p}$ & $\mathrm{y}$ & ${ }^{6} \mathrm{Li}+\mathrm{p} \rightarrow{ }^{4} \mathrm{He}+{ }^{3} \mathrm{He}$ & $\mathrm{y}$ \\
\hline${ }^{3} \mathrm{H}+\mathrm{p} \rightarrow{ }^{3} \mathrm{He}+\mathrm{n}$ & $\mathrm{y}$ & ${ }^{6} \mathrm{Li}+\mathrm{d} \rightarrow{ }^{4} \mathrm{He}+{ }^{4} \mathrm{He}$ & \\
\hline Breakup Reactions & & ${ }^{7} \mathrm{Li}+\mathrm{p} \rightarrow{ }^{4} \mathrm{He}+{ }^{4} \mathrm{He}$ & $\mathrm{y}$ \\
\hline $\mathrm{d}+\mathrm{n} \rightarrow \mathrm{n}+\mathrm{n}+\mathrm{p}$ & & ${ }^{7} \mathrm{Li}+\mathrm{p} \rightarrow{ }^{4} \mathrm{He}+{ }^{4} \mathrm{He}+\gamma$ & \\
\hline $\mathrm{d}+\mathrm{p} \rightarrow \mathrm{n}+\mathrm{p}+\mathrm{p}$ & & ${ }^{7} \mathrm{Li}+\mathrm{d} \rightarrow{ }^{4} \mathrm{He}+{ }^{4} \mathrm{He}+\mathrm{n}$ & $\mathrm{y}$ \\
\hline \multirow[t]{2}{*}{$\mathrm{d}+\gamma \rightarrow \mathrm{n}+\mathrm{p}$} & $\mathrm{y}$ & ${ }^{7} \mathrm{Be}+\mathrm{d} \rightarrow{ }^{4} \mathrm{He}+{ }^{4} \mathrm{He}+\mathrm{p}$ & $\mathrm{y}$ \\
\hline & & ${ }^{7} \mathrm{Be}+\mathrm{n} \rightarrow{ }^{4} \mathrm{He}+{ }^{4} \mathrm{He}$ & $\mathrm{y}$ \\
\hline
\end{tabular}




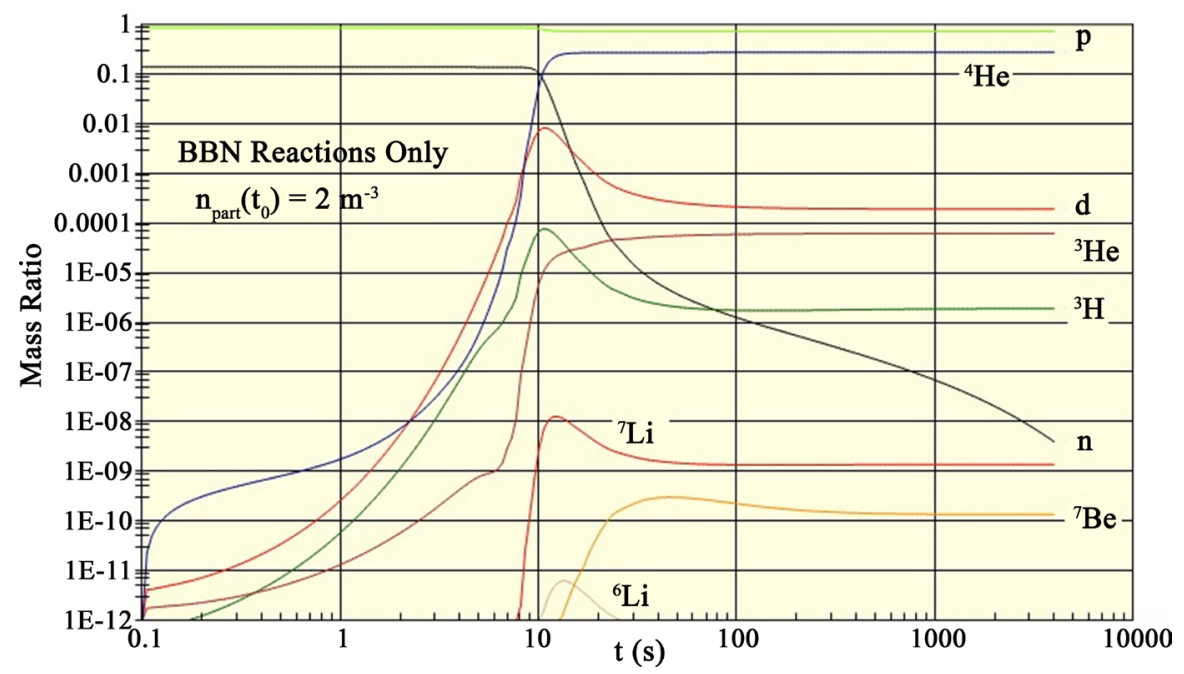

Figure 1. Nucleosynthesis reaction with only BBN reactions included.

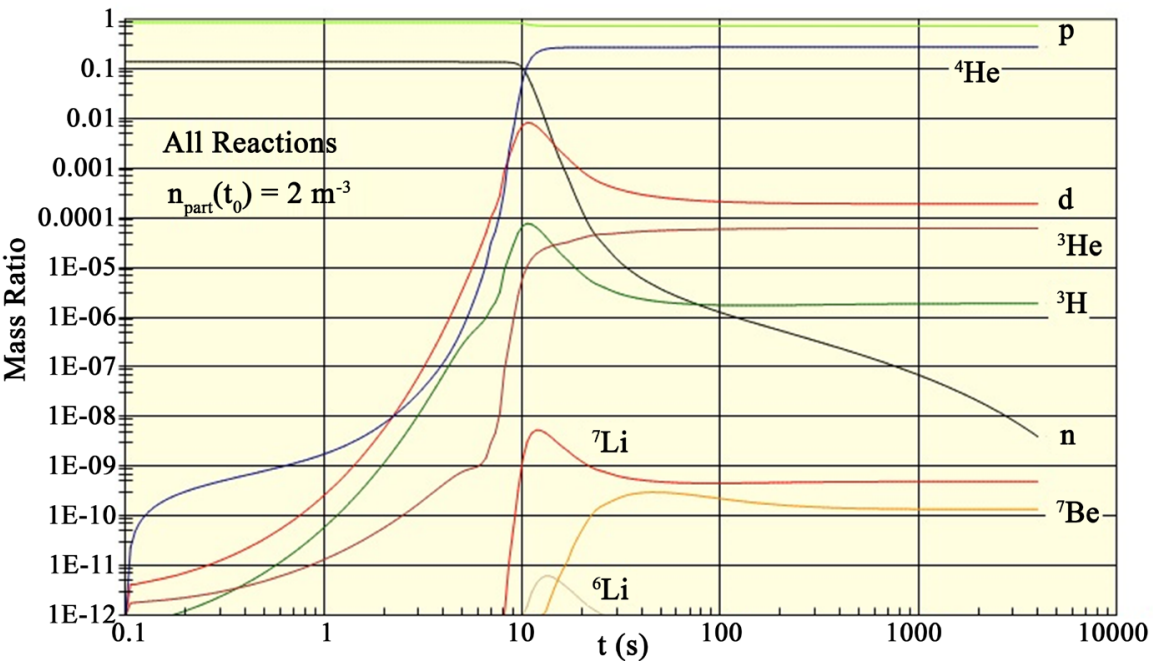

Figure 2. Nucleosynthesis reaction with all reactions included.

the results corresponding to a present-day particle density of $n_{\text {part }}\left(t_{0}\right)=2 m^{-3}$. In Figure 1, we show the results obtained using just the reactions included in the BBN simulation model and in Figure 2, the results obtained with all the reactions included. The only difference between these two simulations is the list of reactions included. Comparing, we see that, with the exception of Lithium, the results are the same. For lithium, however, we find that the BBN calculation predicts a significantly larger density of ${ }^{7} \mathrm{Li}$ than does the calculation including all the reactions.

The ratio is 2.8 which is exactly the value needed to explain the Lithium problem.

\section{Conflicts of Interest}

The author declares no conflicts of interest regarding the publication of this paper. 


\section{References}

[1] Botke, J.C. (2020) A Different Cosmology—Thoughts from Outside the Box. Journal of High Energy Physics, Gravitation and Cosmology, 6, 573-566.

https://doi.org/10.4236/jhepgc.2020.63037

[2] Arbey, A., Auffinger, J., Hickerson, K.P. and Jenssen, E.S. (2018) AlterBBN v2: A Public Code for Calculating Big-Bang Nucleosynthesis Constraints in Alternative Cosmologies. https://arxiv.org/abs/1806.11095 